\title{
CENTRO PARROQUIAL EN "CIUDAD DE LOS POETAS". AVDA. NUEVA DE SACONIA, S/N. MADRID
}

Arquitectos:

Carmen Bravo Durá, María del Pilar Contreras Merino, Jaime Martinez Ramos, José L. de Miguel Rodríguez.

Colaborador:

Javier Garcia-Vaquero Alvaro (estudiante de Arquitectura).

$148-165$

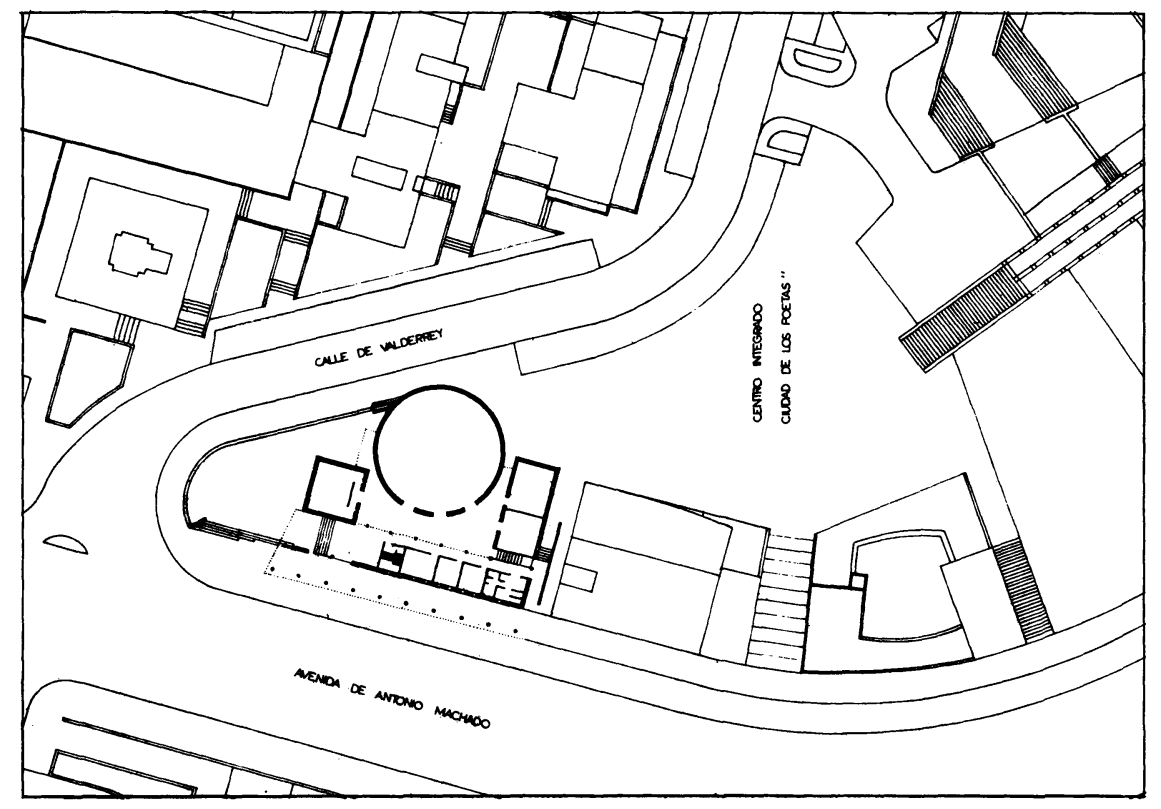

\section{MEMORIA}

El Plan Parcial de la Zona reserva una parcela de forma hexagonal para Centro Parroquial. Esta condición, que puede parecer extraña, obliga mucho la solución del proyecto.

El programa fijado por la propiedad insistía en un aspecto importante: la creación de un gran vestíbulo (el antiguo significado de atrio) como lugar de relación de la vida parroquial. Esta pieza debería articular el conjunto de las diferentes actividades del Centro. Por otro lado, se nos pidió plantear la Capilla de uso diario como lugar de oración independiente de la nave o templo.

Realizadas diferentes propuestas fue aceptada la que se desarrolla. En ella se plantean las piezas que componen el conjunto, como elementos independientes relacionados por el vestibulo antes citado. Cada uno tiene su propia forma y altura. Una cubierta sobreeleva. da los unifica. El pavimento uniforme sirve de nexo de unión entre ellos y configura el espacio central al que dan las entradas de los distintos locales; se jerarquiza su importancia con una geometría de dos ejes creados por las tensiones de los cuatro volúmenes.
El acceso se realiza a través de un amplio hueco que se conecta a lá acera pública por una plataforma, en parte escalonada, que enfatiza el carácter público del edificio.

A la calle se ofrece una pieza rectangular que en planta baja alberga los despachos; y en la primera, dos viviendas. El hueco de entrada incluye el acceso a éstas, separada del correspondiente al Centro por un muro de piedra que se proyecta hacia el exterior. Esta fachada principal escamotea el tratamiento de huecos de las viviendas, para adecuarse al esquema conceptual del edificio, mediante un rasgado de hueco total y retranqueo de las viviendas sobre una galería corrida y abierta al exterior.

El templo se desarrolla como una pieza circular. Se realiza en ladrillo, embutiéndose en su interior cuatro pilares de sección variable que sostienen la cubierta ligera suspendida de tirantes oblícuos. Esta tiene forma cuadrada en planta y define contra el círculo perimetral una iluminación central indirecta. A su vez la cubierta se gira $45^{\circ}$ sobre los ejes del Centro, formando uno nuevo que se orienta hacia la entrada principal. 
Entendido el espacio vestíbulo como exterior, los materiales se confunden con los de la fachada. Prácticamente todo se construye en ladrillo visto rematado y perfilado con chapas metálicas en los huecos.

El solado de las zonas comunes se realiza en terrazo continuo marcando la trama de $1,80 \times 1,80$ que estructura el edificio. Este tramado se gira en el templo, donde la forma de la cubierta se proyecta en la forma del solado.

Las cerrajerías exteriores se proyectan en perfileria metálica Perfrisa, y los huecos se protegen con un entramado ligero de $60 \times 120$ milímetros.

La carpintería interior se pintará para, con los pilares y otros elementos del interior, aportar el color al interior del edificio.

La aclimatación del edificio, partiendo de su uso intermitente y no simultáneo, pretende lograrse por radiación bajo el suelo con energía eléctrica. La posibilidad de corte y control diferenciado en las distintas zonas y locales hacen rentable la electricidad frente a otros combustibles, sólo mejores si el tiempo de utilización es relativamente elevado y la simultaneidad de uso en todo el edificio es alta.

NOTA: Esta Memoria se transcribe tal y como aparece en EL CROQUIS n. ${ }^{\circ}$ 13-14.

\section{ANEJO A LA MEMORIA}

La descripción anterior corresponde al proyecto que se comenta realizado en enero de 1983.

Posteriormente, y por razones largas de explicar y que carecen de interés en una publicación de este tipo, se cambió la ubicación del edificio a un nuevo solar situado en la misma zona pero que, lógicamente, no reunía las mismas condiciones de altimetría y planimetría.

Una condición ineludible era, sin embargo, que se mantuviera el mismo proyecto.

De una situación exenta inscrito en un parque, habia pasado a una situación urbana pegado a una calle y con la incorporación obligatoria de un pórtico que le ligaba a otros edificios.

Tan sólo se nos permitió invertir el edificio sobre uno de sus ejes y modificar los accesos, para mejor adaptarse a su nueva situación, que es a la que se refiere el plano que se adjunta.
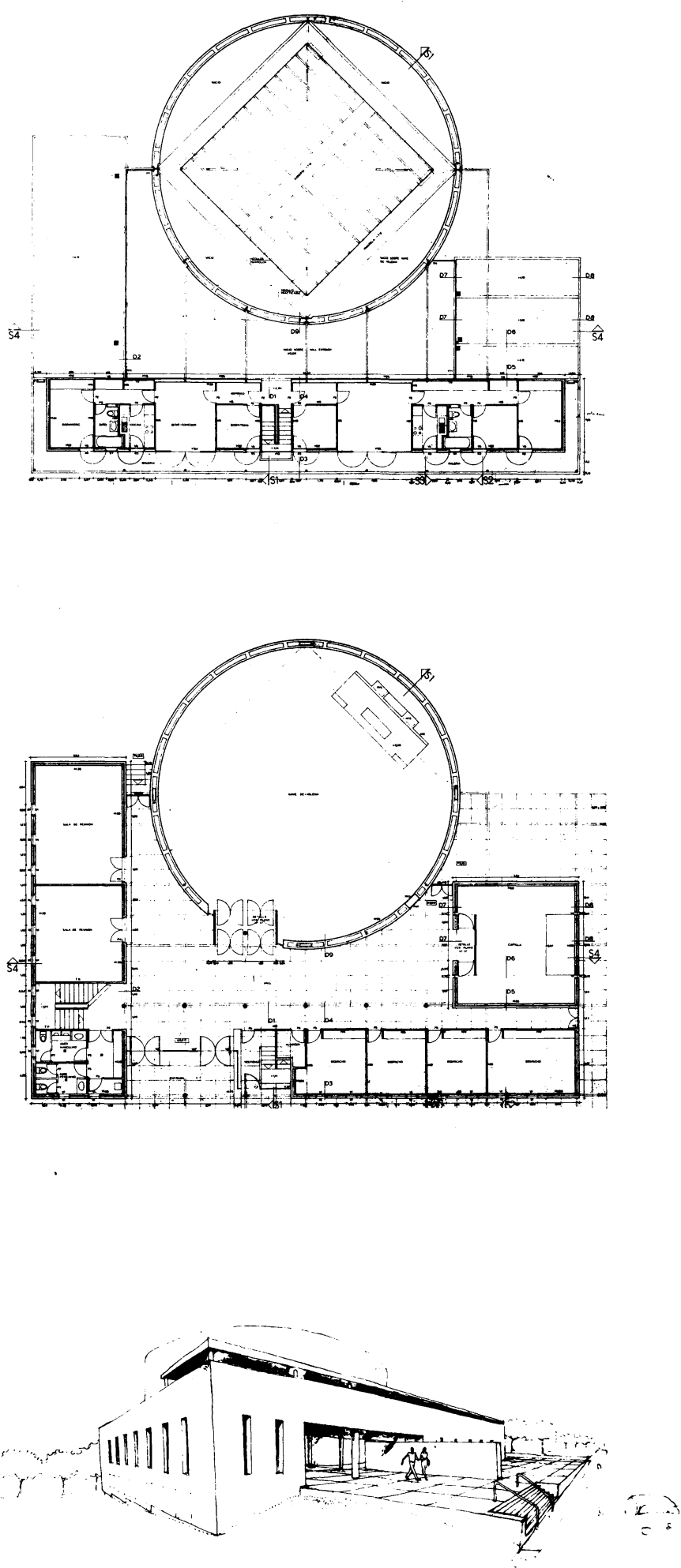

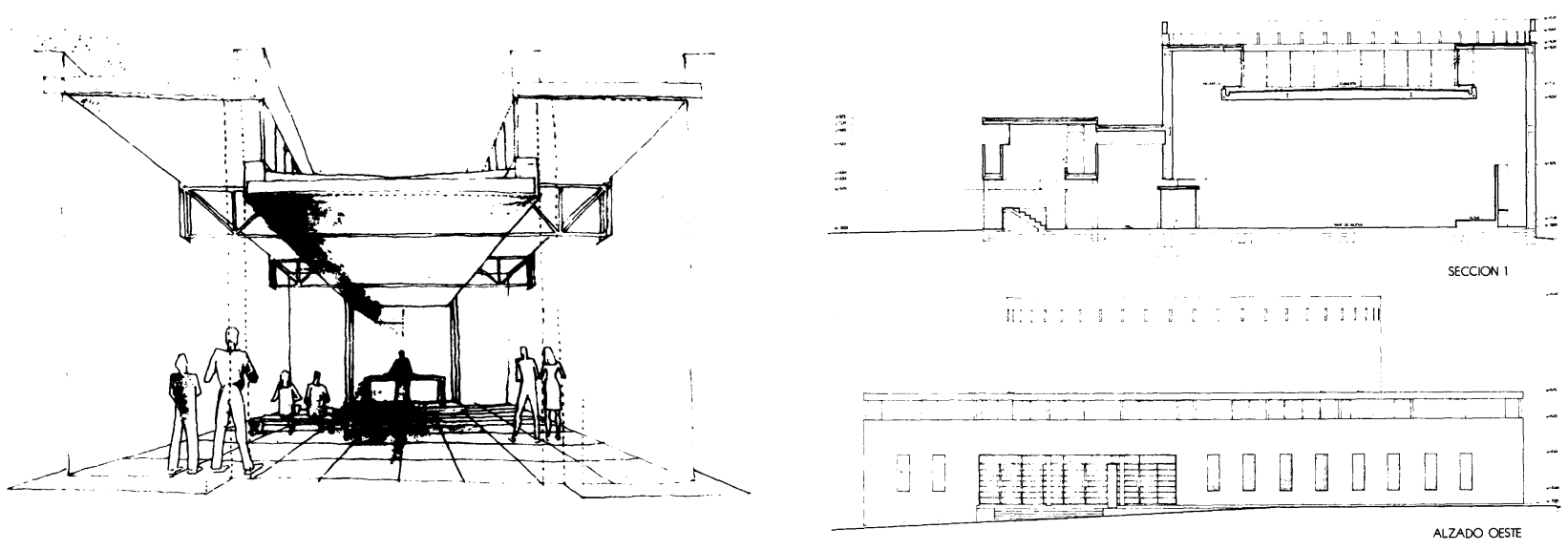

Perspectiva del interior de la sala pequeña.

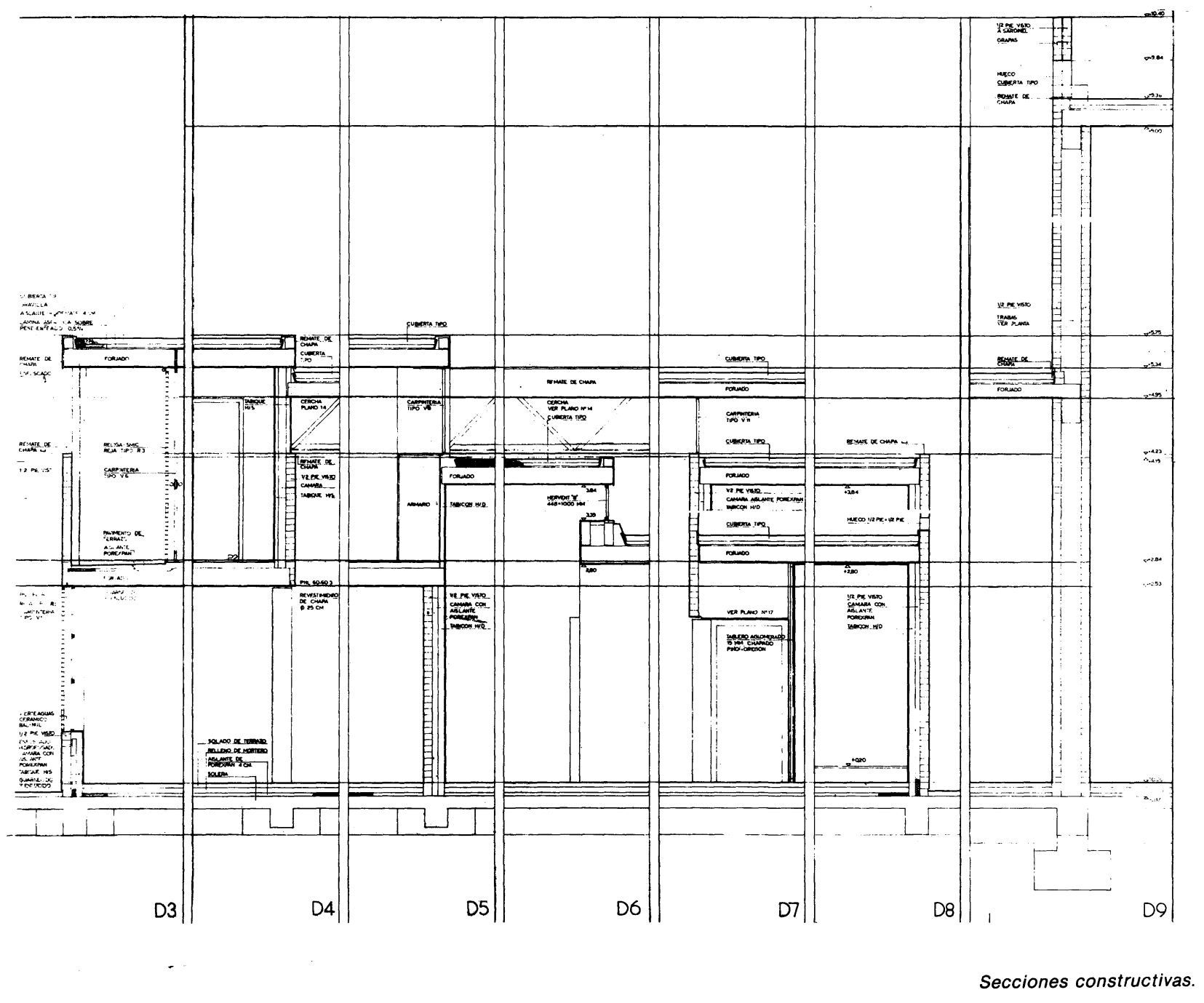



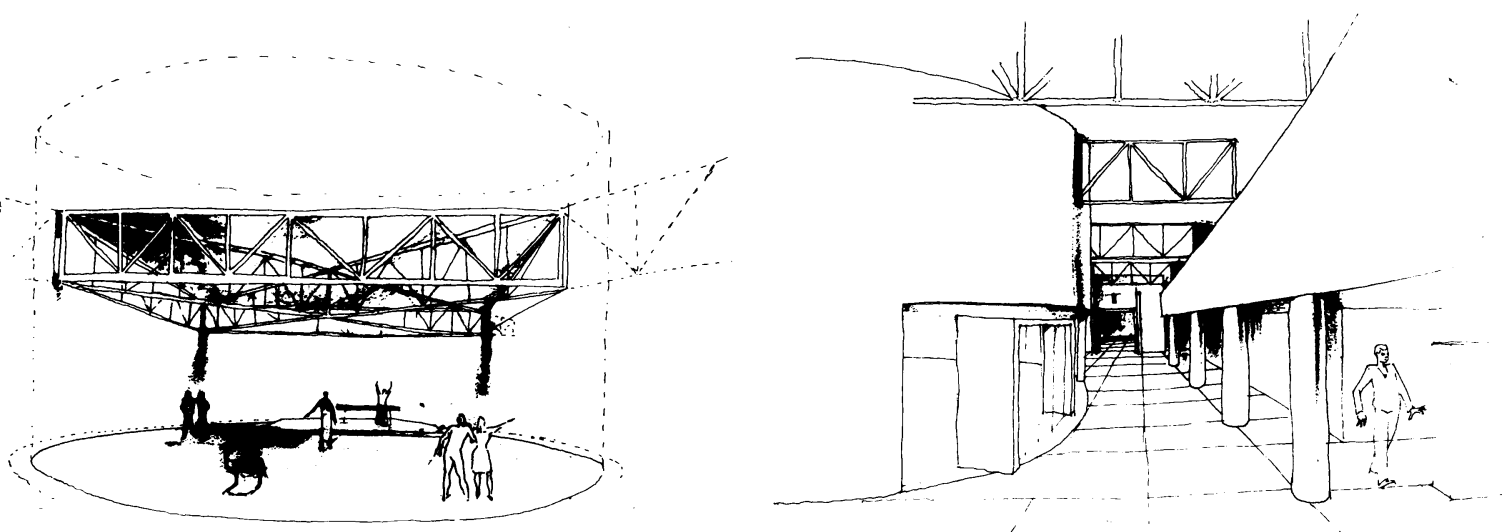

Perspectiva del hall.

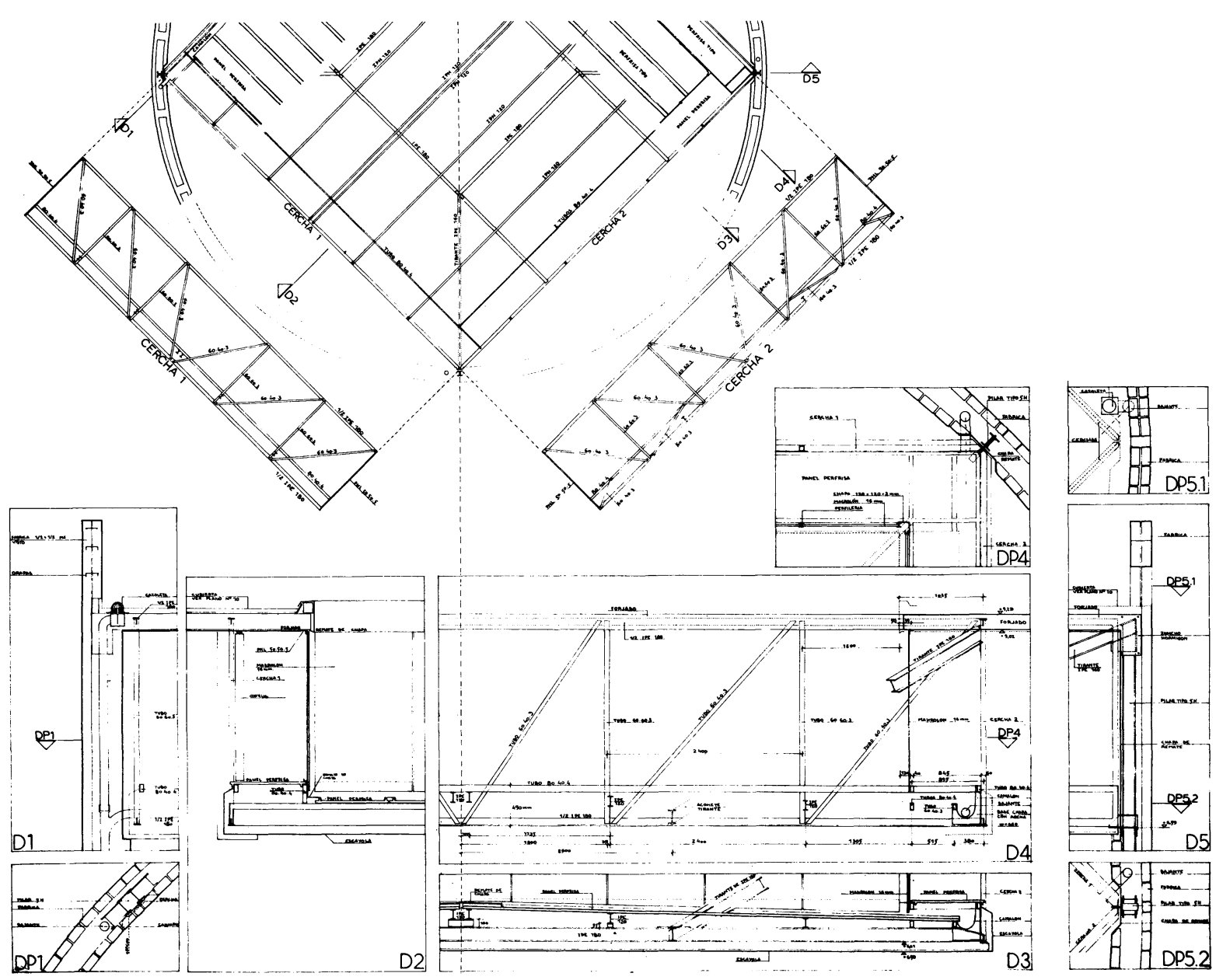

